\title{
The expression of human papillomavirus type 16 (HPV16 E7) induces cell cycle arrest and apoptosis in radiation and hypoxia resistant glioblastoma cells
}

\author{
SUNG-UNG MOON ${ }^{1}$, SOO KYOUNG CHOI ${ }^{2}$, HAN JO KIM ${ }^{2}$, KIRAN KUMAR BOKARA ${ }^{1}$, \\ KYUNG AH PARK ${ }^{1}$, WON TAEK LEE ${ }^{1}$ and JONG-EUN LEE ${ }^{1,2}$ \\ ${ }^{1}$ Department of Anatomy; ${ }^{2}$ BK 21 Project for Medical Science, \\ Yonsei University College of Medicine, Seoul 120-752, Republic of Korea
}

Received April 14, 2011; Accepted August 9, 2011

DOI: $10.3892 / \mathrm{mmr} .2011 .561$

\begin{abstract}
. p53 is a widely known tumor-suppressor gene product that plays a key role in apoptotic cell death induced by DNA-damaging chemotherapeutic agents. Human glioma cells with functional p53 are known to be more resistant to $\gamma$-radiation. The aim of this study was to investigate whether the mutant glioblastoma cells (U87MG) transfected with human papilloma virus-type 16 E7 (HPV16 E7) genes were capable of increasing sensitivity towards irradiation and hypoxia-induced cell death. The pLXSN retroviral vector expressed HPV-16E7 genes and was infected into the p53 mutated U87MG cell line. A specific amplification band of HPV16 E7 genes was detected in E7 genes and transfected in the U87MG cell line using a reverse transcriptase polymerase chain reaction. The experimental groups included the mutant glioblastoma cell line (U87MG), empty vector (pLXSN) transfected to mutant glioblastoma cell line (U87MG-LXSN), and retrovirus carrying HPV16 E7 genes transfected to the mutant glioblastoma cell line (U87MG-E7). Hypoxic conditions were optimized using LDH assay and the subjects were exposed to hypoxia (16 and $20 \mathrm{~h}$ ) and irradiation $(9 \mathrm{~h})$. Hoechst-propidium iodide (PI) staining results showed that hypoxia and irradiation increased the number of dead cells in the U87MG-E7 cells compared to U87MG and U87MGLXSN cells. Results of the FACS analysis showed a similar pattern and recorded 80.44 and $58.94 \%$ of apoptotic cells in U87MG-E7 and U87MG cells, respectively. Cell cycle analysis by FACS revealed that, following irradiation and hypoxia, cells showed G2-M arrest. Additionally, the Western blot analysis results showed altered expression of E2F-1, Rb and p53 in the irradiation- and hypoxia-induced U87MG-E7 cells compared to U87MG and U87MG LXSN cells. In conclusion,
\end{abstract}

Correspondence to: Professor Jong-Eun Lee, Department of Anatomy, Yonsei University College of Medicine, 134 Shinchon-dong, Seodaemun-gu, Seoul 120-752, Republic of Korea

E-mail: jelee@yuhs.ac

Key words: hypoxia, glioma, radiation, HPV16 E7 the over-expression of HPV16 E7 genes in U87MG cell lines increasd cell apoptosis and E2F1 expression compared to the HPV non-infected U87MG cells following irradiation and hypoxia. These results indicate that tumor-specific therapies that increase sensitivity towards radiation and hypoxic conditions may be beneficial for suppression of cancers.

\section{Introduction}

A glioma is a type of tumor that starts in the brain or spine, and whose name derives from glial cells. Its most common site is the brain and it is divided into four stages according to the WHO classification (1). Although grades III and IV are malignant, the prognosis for these types of tumors are relatively different $(2,3)$. Malignant brain tumors, particularly glioblastomas, are notorious for their resistance to therapy (4).

Glioblastomas are known to resist radiotherapy and chemotherapy. Besides other intrinsic properties, the presence of hypoxia in these tumors may be significant in determining resistance to radiation treatment (5-9). However, the underlying molecular mechanism(s) of their radioresistance, as well as radiation-induced apoptotic death of glioma cells has yet to be elucidated.

DNA-damaging agents, used to treat malignant tumors, induce tumor cell apoptosis (10). Radiation-induced DNA damage and cytotoxicity are crucial in understanding tumorigenesis and for optimizing radiation therapy. Increased radiosensitivity and constant radiosensitivity have been associated with $\mathrm{p} 53$ function in various studies as $\mathrm{p} 53$ is frequently mutated or inactivated in human gliomas.

p53 stimulates transcriptional activation to regulate cell-cycle control, DNA repair and synthesis, and apoptosis $(11,12)$, and also mediates the apoptotic pathway by inducing caspase-3 activation (13). This p53 stabilization was controlled by the E2F1 cell cycle-regulated transcription factor (14-16). Overexpression of E2F1 in keratinocytes leads to an increased expression of CDK7, BRCA1 and p19ARF, which in turn increase p53 activity through the mechanisms indicated. This leads to a selective increase in the expression of three downstream targets of $\mathrm{p} 53, \mathrm{Mdm} 2$, cyclin $\mathrm{G}$ and Bax- $\alpha$, thereby predisposing the cells to enter an apoptotic pathway 
via appropriate external stimuli, such as carcinogen-induced DNA damage (17). However, the relationship between p53 gene expression and cellular radiosensitivity remains to be determined (18-24). Previous studies demonstrated the response of p53 gene to radiation therapy in glioblastoma cell lines, U87 expressing wild-type p53 and U87MG expressing mutant-type p53 (25-30).

The human papilloma viruses (HPVs) are small DNAcontaining viruses that exhibit a specific tropism for epithelial cells, and infection with these HPV types leads to a high-risk for the development of malignant disease. The most common of these high-risk HPV types are HPV-16 and HPV-18, shown to encode transforming and immortalizing activities in cultured cells (31-35). The early stage expression protein E7 in HPV-16 has been ascribed to its ability to bind the retinoblastoma $(\mathrm{Rb})$ gene product and leads to stabilization of the p53 tumor suppressor protein through E2F1 activation. Stabilization and accumulation of wild-type p53 usually result in either cell growth arrest or apoptosis. The HPV-16 E7 proteins interfere with several cell cycle checkpoints altering the levels of $\mathrm{E} 2 \mathrm{~F}-1, \mathrm{Rb}$ and $\mathrm{p} 53$ in response to DNA damage (36-39).

In this study, we primarily investigated the effect of HPV-16 E7 genes in glioblastomas. Notably, over-expression of the HPV-16E7 genes that affect the cell cycle at a specific check point should have a more profound effect on tumor suppression therapy.

\section{Materials and methods}

Cell culture. The human glioma cell line U87MG containing the wild-type p53 gene was purchased from the American Type Culture Collection (ATCC, Rockville, MD, USA). The cells were maintained in Dulbecco's modified Eagle's medium (DMEM, Gibco-BRL, Grand Island, NY, USA) supplemented with $10 \%(\mathrm{v} / \mathrm{v})$ fetal bovine serum (FBS) (Gibco-BRL) and $10 \mathrm{~g} / \mathrm{ml}$ penicillin/streptomycin (Gibco-BRL) in a humidified atmosphere containing $5 \% \mathrm{CO}_{2}$ at $37^{\circ} \mathrm{C}$.

Expression of HPV16 E7 genes in glioma cells (U87MG). The HPV16 E7 gene was amplified using E7 specific primers (sense, 5'-GAT GGT CCT GCT GGA CAA GC-3' and antisense, 5'-GGA TCA GCC ATG GTA GAT TAT GG-3') for 35 cycles, programmed as: initial denaturation for $5 \mathrm{~min}$ at $95^{\circ} \mathrm{C}$ followed by $1 \mathrm{~min}$ at $95^{\circ} \mathrm{C}, 1 \mathrm{~min}$ at $50^{\circ} \mathrm{C}$, and $1 \mathrm{~min} 72^{\circ} \mathrm{C}$. Following this step, a final extension was carried out at $72^{\circ} \mathrm{C}$ for $10 \mathrm{~min}$. The retroviral vector pLXSN was used to express the E7 genes of HPV-16 containing the neomycin-resistance gene to the U87MG cell line with wild-type p53 gene. The construction and generation of the retroviruses was described by Halbert et al (40). Glioma cells expressing the viral genes were selected in $400 \mu \mathrm{g} / \mathrm{ml} \mathrm{G} 418$ (Gibco-BRL) for 5 days. Stably proliferating cells were screened for E7 mRNA expression by reverse transcription polymerase chain reaction (RT-PCR).

$R T$-PCR. Total RNA was isolated and purified with TRIzol reagent (Invitrogen, Carlsbad, CA, USA) according to the manufacturer's instructions. The obtained RNA was quantitated by measuring the absorbance at $260 \mathrm{~nm}$. Synthesis of cDNA from mRNA and the normalization of the samples were carried out by RT-PCR. Amplification of E7 cDNA was carried out for 35 cycles, programmed as: initial 5 min denaturation at $95^{\circ} \mathrm{C}$ followed by $1 \mathrm{~min}$ at $95^{\circ} \mathrm{C}, 1 \mathrm{~min}$ at $50^{\circ} \mathrm{C}$, and $1 \mathrm{~min} 72^{\circ} \mathrm{C}$. Following this step, a final extension was carried out at $72^{\circ} \mathrm{C}$ for $10 \mathrm{~min}$. The sequences of the specific primers were as follows: sense, 5'-GAT GGT CCT GCT GGA CAA GC-3' and antisense, 5'-GGA TCA GCC ATG GTA GAT TAT GG-3' for the E7 virus protein. The PCR products were separated by electrophoresis in $1.5 \%$ agarose gels stained with ethidium bromide.

Hypoxia treatment or $\gamma$-irradiation. The response of the cells to low-oxygen environment and radiation was assessed by subjecting the cells to hypoxia and irradiation. In brief, cells were incubated in an anaerobic culture chamber (Forma Scientific Anaerobic chamber) at $0 \%$ oxygen for 16 or $20 \mathrm{~h}$ followed by 9 h of radiation using Gammacell 3000 Elan.

Measurement of lactate dehydrogenase (LDH) activity. Cell death was quantified by assaying $\mathrm{LDH}$ release into the culture medium. Different time points were selected and the percentage of LDH release was determined. The total amount of LDH released from $100 \%$ cell death, termed 'full kill', was determined at the end of the experiment by freezing the cells at $-80^{\circ} \mathrm{C}$ followed by rapid thawing. The extent of cell death was expressed as a percentage of full kill. The percentage of LDH was calculated against the percentage of full kill (41).

Determination of apoptosis and cell cycle. For cell cycle analysis U87MG, U87MG-pLXSN and U87MG-E7 cells were harvested, washed with phosphate-buffered saline (PBS) and fixed in $70 \%$ ethanol. Propidium iodide (PI) $(50 \mathrm{mg} /$ $\mathrm{ml}$ in PBS, containing $100 \mathrm{mg} / \mathrm{ml}$ RNase A) was added for 5 min. DNA content was analyzed using a FACScan (BectonDickinson, Mountain View, CA, USA). The cell population in each cell-cycle phase was determined by CellQuest software (Becton-Dickinson Immunocytometry Systems, San Jose, CA, USA).

The experimental groups subjected to hypoxia and radiation injury were stained with Hoechst 33258/PI to determine the apoptotic cells. Briefly, 2-3 $\mu \mathrm{g} / \mathrm{ml}$ Hoechst 33258 dye (Sigma, St. Louis, MO, USA) was added to the culture medium for $20 \mathrm{~min}$ and then the samples were maintained at $37^{\circ} \mathrm{C}$ for $30 \mathrm{~min}$. PI solution $(2-5 \mu \mathrm{g} / \mathrm{ml})$ was then added prior to observation under a fluorescent microscope (Olympus Diaphot, Tokyo, Japan) (42). Cell injury was evaluated morphologically by counting Hoechst-positive, PI-positive, Hoechst-positive, and PI-negative cells as non-viable and viable, respectively.

Western blot analysis. The U87MG, U87MG pLXSN and U87MG-E7 cells were washed twice with PBS and lysed in cold lysis buffer containing protease inhibitor cocktail. The cells were incubated at $4^{\circ} \mathrm{C}$ for $1 \mathrm{~h}$, and then centrifuged for $30 \mathrm{~min}$ at $12,000 \mathrm{rpm}$ at $4^{\circ} \mathrm{C}$. The protein concentration was determined using the BCA protein assay (Pierce, Rockford, IL, USA), and soluble protein $(30 \mu \mathrm{g})$ was resolved by sodium dodecyl sulfate-polyacrylamide gel electrophoresis (SDS-PAGE). The separated proteins were then electrotransferred onto nitrocellulose membrane (Millipore, Billerica, 
MA, USA) using standard procedures. The membranes were blocked with $5 \%$ dry milk in TBS $(10 \mathrm{mM}$ Tris- $\mathrm{HCl} \mathrm{pH} 7.5$, $150 \mathrm{mM}$ sodium chloride) for $3 \mathrm{~h}$ and were then incubated with primary antibodies for $1 \mathrm{~h}$. The antibodies used were mouse monoclonal anti-p53 antibody, (Santa Cruz Biochemistry, Santa Cruz, CA, USA), mouse monoclonal anti-pRb antibody (Santa Cruz Biochemistry), and rabbit polyclonal anti-E2F-1 antibody (Santa Cruz Biochemistry). After incubation with primary antibodies the membranes were washed with TBS solution, and were then incubated with respective secondary antibodies: HRP-goat anti-mouse IgG conjugate (Zymed Laboratories, San Francisco, CA, USA) and anti-rabbit IgG, (Amersham, Piscataway, NJ, USA), using the ECL kit according to the manufacturer's instructions (Amersham).

\section{Results}

Retroviral infection of human papilloma virus E7 (HPV16 E7) genes in glioblastoma cell line (U87MG) induced strong endogenous transgene expression. The human papillomavirus (7.9 bp, Fig. 1A) is divided into early (E) and late (L) stage expression protein regions, containing seven early and two late open reading frames (ORFs), and a non-coding URR containing the origin of DNA replication and binding sites for numerous transcription factors. Primers were designed for the detection of HPV16 E7 genes with the sense primer starting at $676 \mathrm{bp}$ and the anti-sense primer ending at $875 \mathrm{bp}$. RT-PCR data (Fig. 1B) showed a specific amplification band (200 bp) in the HPV16 E7 genes infected to the U87MG cell line (Lane 1). However, the retrovirus non-infected U87MG cell

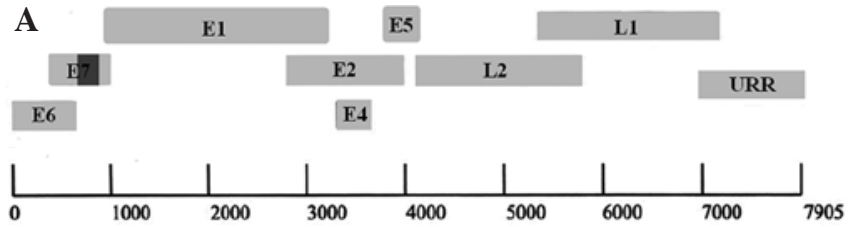

Forward primer : 5'- GAT GGT CCT GCT GGA CAA GC-3' Reverse primer : 5'- GGA TCA GCC ATG GTA GAT TAT GG-3'

B

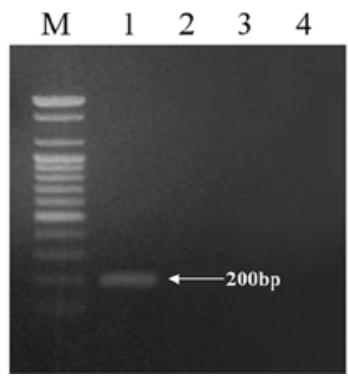

M : 100 bp marker

1 : U87MG-E7

2 : U87MG-LXSN

3: $\mathrm{U} 87 \mathrm{MG}$

4 : Negative control

Figure 1. Cloning of human papilloma-virus type 16 (HPV 16) in a U87MG cell line. (A) Genomic organization of HPV16 and the cloning site. The HPV genome constitutes regions labeled L (late), E (early) and URR (upstream regulatory region). Dark gray box of E7 site is used for cloning into the retrovirus vector using restriction enzyme digestion. (B) The gels were stained with ethidium bromide and images were captured with a UV light to confirm the retroviral transfection of the E7 gene expression in the U87MG cell line. Detection of the transgenic expression of E7 genes was performed using E7 gene primers by RT-PCR. M is 100 bp DNA marker. Lane 1, RT-PCR amplification band of HPV16 E7 genes (200 bp) in U87MG cells transfected with the retrovirus vector (pLXSN containing HPV16 E7 genes). Lane 2, RT-PCR of U87MG cells infected with pLXSN without E7 gene insert. Lane 3, U87MG cells. Lane 4, negative control.

A

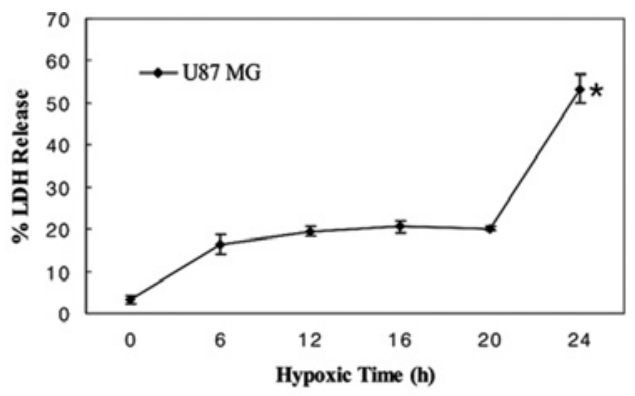

B

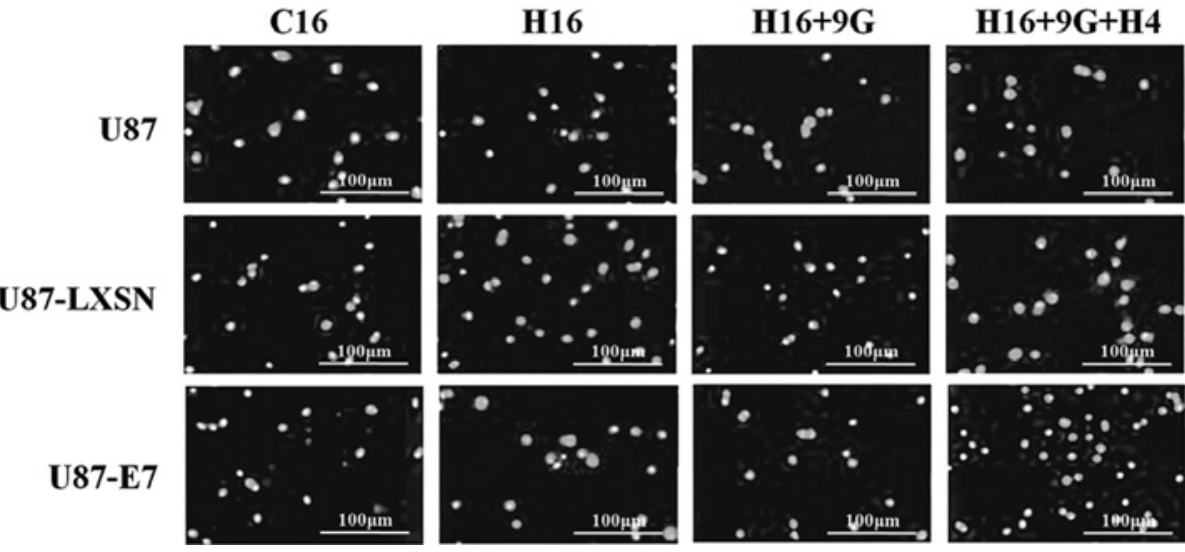

Figure 2. Hypoxia-induced cell death in human glioma cells was detected by LDH assay. (A) A total of 55\% of LDH release was recorded after $24 \mathrm{~h}$ of hypoxic injury in U87MG cells. The experiment was repeated three times and the result was shown as the mean \pm SE, ${ }^{*} \mathrm{P}<0.01$. (B) The U87MG, U87MGLXSN and U87MG-E7 cells after hypoxia, hypoxia-irradiation and hypoxia-irradiation-hypoxia were stained with $10 \mu \mathrm{M}$ of Hoechst $33258 / \mathrm{PI}$ for 10 and $1 \mathrm{~min}$, respectively, to determine the dead cells under a fluorescent microscope (magnification, $\mathrm{x} 200$ ). 


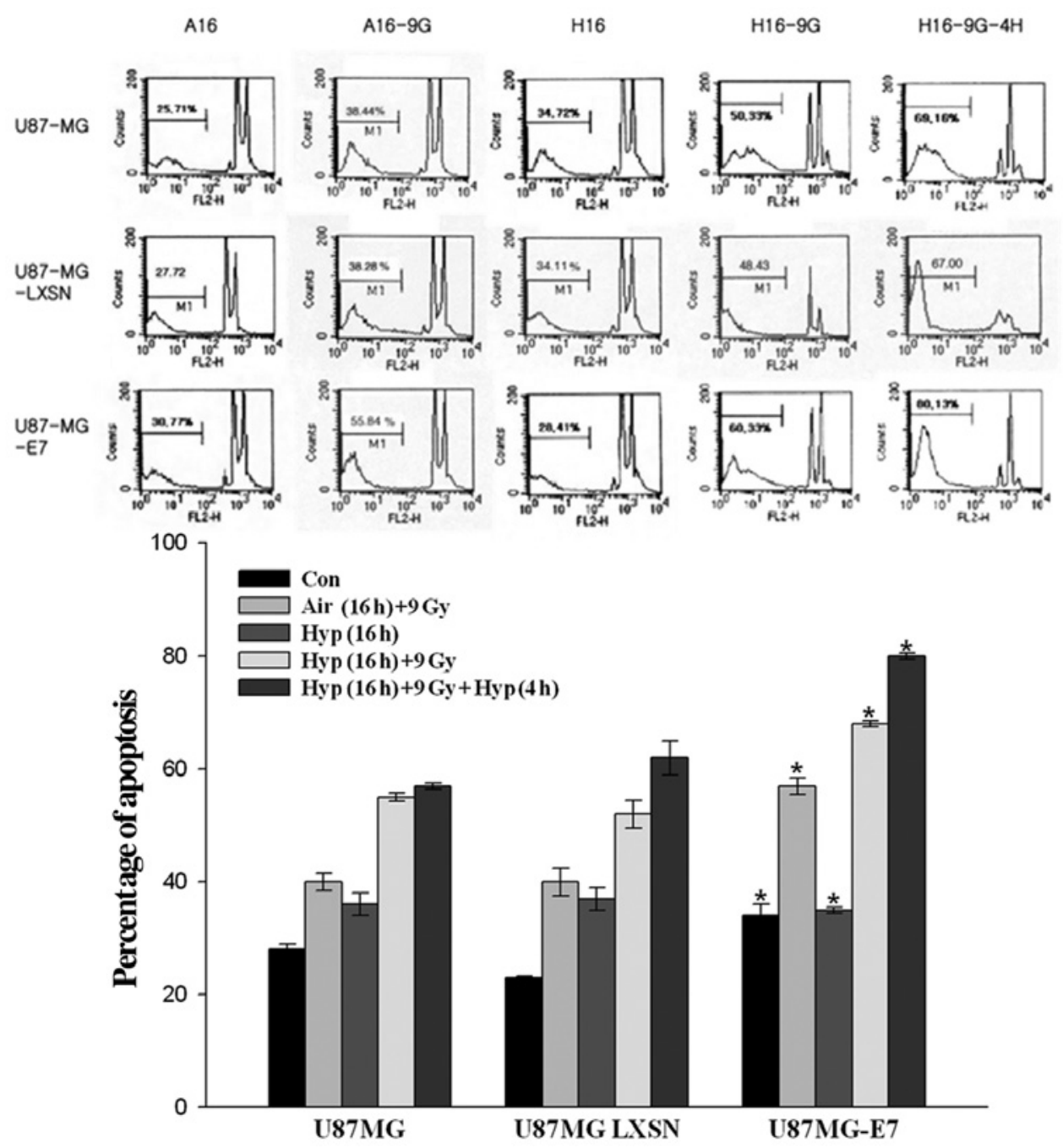

Figure 3. Effect of HPV16 E7 transgene expression in U87MG cells subjected to hypoxia and radiation. The experimental groups (U87MG, U87MGLXSN and U87MG E7) were exposed to hypoxia (16 and $20 \mathrm{~h}$ ) and irradiation $(9 \mathrm{~h})$ stained with PI. FACS analysis was performed to analyze the cell cycle. Values are the percentage of apoptotic cells using CellQuest software. Results are shown as the average of three different experiments; mean \pm SE. "P<0.01, significant difference between the data pertaining to U87MG and the remaining cell lines.

line and the pLXSN infected U87MG cell line did not show any endogenous expression of HPV16 E7 genes (Lanes 2 and 3). $\mathrm{M}$ is the $100 \mathrm{bp}$ DNA ladder marker and Lane 4 is the negative control.

Radiation- and hypoxia-induced apoptosis in U87MG cells expressing E7 genes. LDH assay was performed to optimize the condition for hypoxia in the U87 human glioma cell line at different time periods. Approximately 20 and $53.3 \%$ of LDH release was recorded in U87MG cells subjected to hypoxia at 20 and 24 h, respectively (Fig. 2A). Based on the LDH data, hypoxia of 16 and $20 \mathrm{~h}$ were adapted for Hoechst/PI and FACS analysis. Hoechst/PI staining showed an increase in the apoptotic cell death and marked morphological changes in the U87MG-E7 cell line compared to the E7 non-transfected experimental groups (U87MG and U87MG-LXSN) subjected to hypoxia and irradiation (Fig. 2B). Results of the FACS analysis revealed that U87MG cells expressing HPV16 E7 genes are more sensitive to radiation and hypoxia (Fig. 3). Four hours after irradiation, the E7-expressing U87MG cells, under hypoxic conditions, recorded $80.44 \%$ of apoptotic cells compared with
U87MG cells (58.94\%). The U87MG-E7 cell line was found to be more sensitive to the radiation under hypoxic conditions.

p53-independent G0-G1 cell cycle arrest in U87MG cells expressing HPV16 E7 genes subjected to hypoxia and radiation. DNA-damaging agents, such as hypoxia or ionizing radiation, induce a nuclear accumulation of the p53 tumor suppressor protein. However, most tumor cells lack functional p53 and would not arrest in G1. Thus, the greatest cell cycle perturbation of an irradiated tumor cell was detected in the delay in the transition from the $\mathrm{G} 2$ to $\mathrm{M}$ phase. A prolonged arrest in G2-M after radiation has been associated with increased radioresistance in the human cell line. Under hypoxic conditions, the G0-G1 arrest in U87MG glioblastoma cells expressing wild-type p53 was determined using CellQuest software (Becton-Dickinson Immunocytometry Systems) and the induction of the E2F-1 and $\mathrm{Rb}$ proteins of these cells was detected using Western blotting. The U87MG cells after irradiation under hypoxic conditions showed G2-M arrest due to an increased expression of p53 and decreased cell levels of Rb and E2F-1 proteins (Fig. 4A,B). In the HPV16 E7 
A
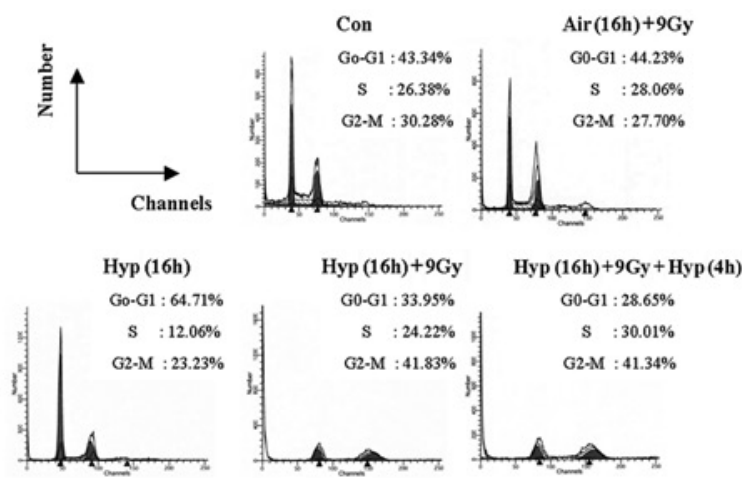

C
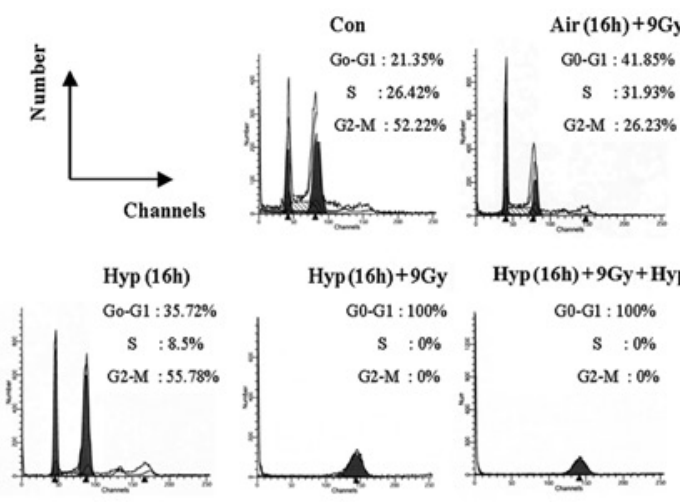

Hyp (16h)+9Gy+Hyp (4h)

G0-G1 : 100\%

S : $: 0 \%$

G2-M : $0 \%$

D

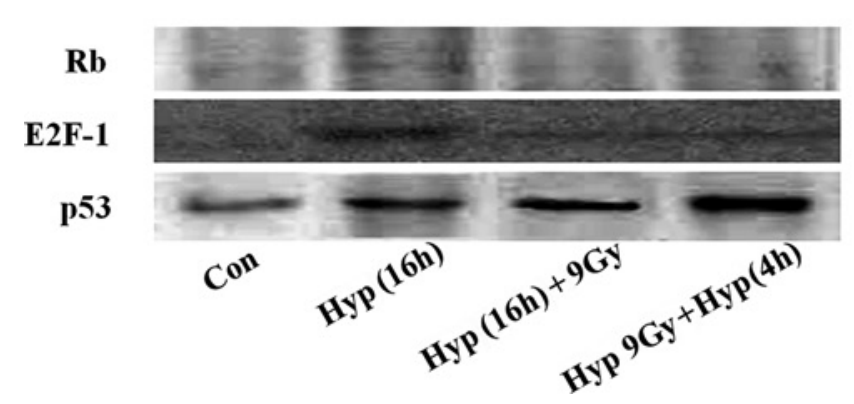

\section{$\mathbf{R b}$}

E2F-1

p53

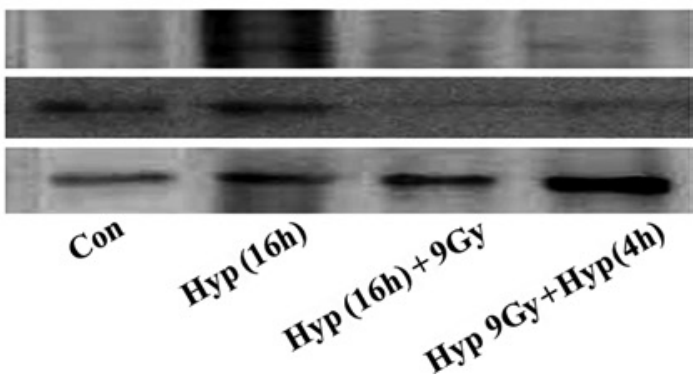

Figure 4. Hypoxia and irradiation induced cellular alterations in U87MG cells before (A and B) and after (C and D) HPV16 E7 gene transfection. (A) FACS analysis of hypoxia and irradiation induced apoptosis in the U87MG cell line. Distributions of DNA content in the cell cycle were shown as a representative of three experiments. (B) Expression of Rb, E2F-1 and p53 proteins in the U87MG cell line by Western blotting. (C) FACS analysis of U87MG-E7 cells exposed to hypoxia and irradiation. Distributions of DNA content were shown as a representative of three experiments. (D) Expression of Rb, E2F-1 and p53 expression in U87MG-E7 cells by Western blotting.

transduced U87MG cell line, however, no cells were trapped in the G2-M phase, indicating that E7 genes induce apoptosis following hypoxia and irradiation (Fig. 4C). Moreover, the cell levels of E2F-1, Rb were markedly decreased following hypoxia and irradiation with an increase in p53 expression demonstrating that E7 genes induced apoptosis independently of p53 (Fig. 4D). Cell cycle analysis by FACS showed G2-M phase arrest and the Western blotting results showed an increase in the E2F-1 expression in the U87MG-E7 cell line compared with U87MG and U87MG-LXSN, whereas p53 expression was not significantly altered.

\section{Discussion}

Grade III and IV gliomas are the most malignant brain tumors encountered in adults and the most frequent solid neoplasms found in children (2,3). In a normal cell, p53-dependent cell-cycle arrest allows enough time for the DNA damaged by agents to be repaired (11). This is often achieved by a disruption of the p53 pathway in the glioblastoma $(3,43,44)$. At least $25 \%$ of glioblastomas have mutations or deletions of the p53 gene itself, and another 5-12\% have amplifications of the locus on chromosome 12, which encodes Mdm2, and which promotes degradation of p53 (2). These tumors are highly resistant to conventional treatments such as surgery, radiotherapy and chemotherapy. Studies exploring other therapeutic potentials for the treatment of tumors, including gene therapy, are currently underway (27). In their study,
Gomez-Manzano et al demonstrated that adenovirusmediated p53 gene delivery in glioma cell lines increased apoptosis (45). However, glioma cells with wild-type p53 did not undergo apoptosis, but showed a slower growth rate, becoming sensitive to radiation treatment $(24,29,46)$, indicating that the function of p53 is regulated by cell conditions and that p53 alone cannot trigger the apoptotic signaling pathway.

Based on the available evidence, apoptotic cell death in the tumors could be p53-independent. Therefore, we aimed to investigate whether the p53 mutated glioblastoma cell line (U87MG) transfected with HPV16 E7 proteins was capable of triggering the apoptotic signaling pathway regardless of $\mathrm{p} 53$ expression. The cloning of HPV16 E7 genes and their transfection into the p53 mutated glioblastoma cell line (U87MG-E7) was performed using the retrovirus expression system. The specific amplicons confirming the integration of the HPV16 E7 genes was detected in U87MG-E7 cells using RT-PCR reaction (Fig. 1). The HPV16 E7 protein deregulates the cell cycle through interactions with a variety of proteins involved in cell cycle control and transcriptional regulation (36). The HPV16 E7 protein binds to $\mathrm{Rb}$ and causes release of the transcription factor E2F-1, which in turn, stimulates cell cycle progression or apoptosis depending on cell cycle conditions $(47,48)$. Mice expressing the human papilloma virus E7 protein in photoreceptors were generated (36). Notably, E7 mice did not develop retinal tumors but showed apoptosis instead. E7 mice crossed with p53-knockout mice tend to develop tumors 
(49). Thus, the status of p53 may determine cell fate. The stabilization of p53 and the concomitant destabilization of pRB that are detected in E7-expressing cells are reminiscent of the effects elicited once DNA damage or a cellular stress signal has been initiated in a cell (36).

The present study suggests that HPV16 E7 genes increased radiosensitivity in a wild-type p53 glioma cell under hypoxic condition hypothesizing that 'high-risk HPV16 E7 genes stimulate apoptosis', which was confirmed by Hoechst/ PI staining and cell cycle analysis (Figs. 2 and 3). In the HPV16 E7 genes non-transfected U87MG cells, the duration of the G2-M arrest was associated with p53 status. However, U87MG cells expressing HPV16 E7 genes, underwent G0-G1 arrest and a large percentage of apoptosis was associated with the stabilization of the p53 expression. On the other hand, it should be noted that the U87MG cells used in this study are resistant to treatment with irradiation and hypoxia, but a large percentage of apoptotic cells were detected in HPV16 E7 genes transfected to the U87MG cell line. HPV16 E7 genes transfected to the U87MG cell line inhibited the pRB pathway. An increase in wild type-p53 protein expression after irradiation provided an additional mechanism for glioma cells to increase radiosensitivity (Fig. 4). Following the FACS analysis, the results indicate that transfection of E7 genes overcomes the resistance mechanism of glioma cells after irradiation under hypoxic conditions by the arrest of the G0-G1 phase in the cell cycle. HPV16 E7 protein binds to Rb and causes release of the transcription factor E2F-1, which in turn, stimulates cell cycle progression or apoptosis depending on cell cycle conditions. HPV16 E7 induced increased levels of p53 expression after irradiation and p53 is essentially required for the G1 checkpoint after irradiation. Evidence suggests that p53 plays a role in the G2 and mitotic checkpoints. Therefore, we investigated the effects of transgene therapy in glioblastoma with HPV16 E7 genes and the relationship between HPV16 E7 gene expression and radiosensitivity in the U87MG cell line by evaluating the degree of cell death and apoptosis. The results of the present study suggest that HPV16 E7 genes increased radiosensitivity in U87MG-E7 cells under hypoxic condition. In U87MG cells, the duration of the G2-M arrest was associated with p53 status, and p53-wild type cells underwent prolonged arrest associated with the elevation of p53 levels. On the other hand, U87MG cells expressing HPV16 E7 genes underwent G0-G1 arrest and a large percentage of apoptosis was associated with the stabilization of $\mathrm{p} 53$ protein expression. The transfer of HPV16 E7 genes to correct the genetic defect appears to be feasible. Therefore, transduction of E7 genes may provide the possibility to overcome the resistance mechanism of glioma cells after irradiation under hypoxia through the arrest of G0-G1 cell cycle with the stabilization of p53.

In conclusion, HPV16 E7 over-expressed U87MG cells resulted in the stabilized expression of p53 under hypoxia conditions. Therefore, this approach may provide insight into the development of $\gamma$-radiation therapy for malignant brain tumors.

\section{Acknowledgments}

This work was supported by the Korea Science and Engineering Foundation (KOSEF) grant funded by the government of Korea (MEST) (No. 2009-00526260).

\section{References}

1. Mamelak AN and Jacoby DB: Targeted delivery of antitumoral therapy to glioma and other malignancies with synthetic chlorotoxin (TM-601). Expert Opin Drug Deliv 4: 175-186, 2007.

2. Wechsler-Reya R and Scott MP: The developmental biology of brain tumors. Annu Rev Neurosci 24: 385-428, 2001.

3. Rasheed BK, Wiltshire RN, Bigner SH and Bigner DD: Molecular pathogenesis of malignant gliomas. Curr Opin Oncol 11: 162-167, 1999.

4. Taghian A, Suit H, Pardo F, et al: In vitro intrinsic radiation sensitivity of glioblastoma multiforme. Int J Radiat Oncol Biol Phys 23: 55-62, 1992.

5. Hockel M and Vaupel P: Tumor hypoxia: definitions and current clinical, biologic, and molecular aspects. J Natl Cancer Inst 93: 266-276, 2001.

6. Lal A, Peters H, St Croix B, et al: Transcriptional response to hypoxia in human tumors. J Natl Cancer Inst 93: 1337-1343, 2001.

7. Alarcon R, Koumenis C, Geyer RK, Maki CG and Giaccia AJ: Hypoxia induces p53 accumulation through MDM2 downregulation and inhibition of E6-mediated degradation. Cancer Res 59: 6046-6051, 1999.

8. Rupnow BA, Alarcon RM, Giaccia AJ and Knox SJ: p53 mediates apoptosis induced by c-Myc activation in hypoxic or gamma irradiated fibroblasts. Cell Death Differ 5: 141-147, 1998.

9. Hockel M, Schlenger K, Mitze M, Schaffer U and Vaupel P: Hypoxia and Radiation Response in Human Tumors. Semin Radiat Oncol 6: 3-9, 1996.

10. Fulda S and Debatin KM: Apoptosis pathways in neuroblastoma therapy. Cancer Lett 197: 131-135, 2003.

11. el-Deiry WS: Regulation of p53 downstream genes. Semin Cancer Biol 8: 345-357, 1998.

12. Moroni MC, Hickman ES, Lazzerini Denchi E, et al: Apaf-1 is a transcriptional target for E2F and p53. Nat Cell Biol 3: 552-558, 2001.

13. Roth W and Reed JC: Apoptosis and cancer: when BAX is TRAILing away. Nat Med 8: 216-218, 2002.

14. Zindy F, Eischen CM, Randle DH, et al: Myc signaling via the ARF tumor suppressor regulates p53-dependent apoptosis and immortalization. Genes Dev 12: 2424-2433, 1998.

15. de Stanchina E, McCurrach ME, Zindy F, et al: E1A signaling to 553 involves the p19(ARF) tumor suppressor. Genes Dev 12: 2434-2442, 1998.

16. Bates S, Phillips AC, Clark PA, et al: p14ARF links the tumour suppressors RB and p53. Nature 395: 124-125, 1998.

17. Wikonkal NM, Remenyik E, Knezevic D, et al: Inactivating E2f1 reverts apoptosis resistance and cancer sensitivity in Trp53-deficient mice. Nat Cell Biol 5: 655-660, 2003.

18. Nozaki M, Tada M, Kobayashi $\mathrm{H}$, et al: Roles of the functional loss of p53 and other genes in astrocytoma tumorigenesis and progression. Neuro Oncol 1: 124-137, 1999.

19. Paunu N, Syrjakoski K, Sankila R, et al: Analysis of p53 tumor suppressor gene in families with multiple glioma patients. J Neurooncol 55: 159-165, 2001.

20. Muschel RJ, Soto DE, McKenna WG and Bernhard EJ: Radiosensitization and apoptosis. Oncogene 17: 3359-3363, 1998.

21. Van Meir EG, Kikuchi T, Tada M, et al: Analysis of the p53 gene and its expression in human glioblastoma cells. Cancer Res 54: 649-652, 1994.

22. Yount GL, Haas-Kogan DA, Vidair CA, Haas M, Dewey WC and Israel MA: Cell cycle synchrony unmasks the influence of p53 function on radiosensitivity of human glioblastoma cells. Cancer Res 56: 500-506, 1996.

23. Kim IA, Yang YJ, Yoon SC, et al: Potential of adenoviral p53 gene therapy and irradiation for the treatment of malignant gliomas. Int J Oncol 19: 1041-1047, 2001.

24. Shono T, Tofilon PJ, Schaefer TS, Parikh D, Liu TJ and Lang FF: Apoptosis induced by adenovirus-mediated p53 gene transfer in human glioma correlates with site-specific phosphorylation. Cancer Res 62: 1069-1076, 2002.

25. Rupnow BA, Murtha AD, Alarcon RM, Giaccia AJ and Knox SJ: Direct evidence that apoptosis enhances tumor responses to fractionated radiotherapy. Cancer Res 58: 1779-1784, 1998.

26. Broaddus WC, Liu Y, Steele LL, et al: Enhanced radiosensitivity of malignant glioma cells after adenoviral p53 transduction. J Neurosurg 91: 997-1004, 1999. 
27. Rudoltz MS, Kao G, Blank KR, Muschel RJ and McKenna WG: Molecular Biology of the Cell Cycle: Potential for Therapeutic Applications in Radiation Oncology. Semin Radiat Oncol 6: 284-294, 1996

28. Tada M, Matsumoto R, Iggo RD, et al: Selective sensitivity to radiation of cerebral glioblastomas harboring p53 mutations. Cancer Res 58: 1793-1797, 1998.

29. Badie B, Goh CS, Klaver J, Herweijer H and Boothman DA: Combined radiation and p53 gene therapy of malignant glioma cells. Cancer Gene Ther 6: 155-162, 1999.

30. Yount GL, Haas-Kogan DA, Levine KS, Aldape KD and Israel MA: Ionizing radiation inhibits chemotherapy-induced apoptosis in cultured glioma cells: implications for combined modality therapy. Cancer Res 58: 3819-3825, 1998.

31. Zhivotovsky B, Joseph B and Orrenius S: Tumor radiosensitivity and apoptosis. Exp Cell Res 248: 10-17, 1999.

32. Lakin ND and Jackson SP: Regulation of p53 in response to DNA damage. Oncogene 18: 7644-7655, 1999.

33. Pykett MJ, Azzam E, Dahlberg W and Little JB: Differential $\mathrm{p} 53, \mathrm{p} 21, \mathrm{mdm} 2$ and $\mathrm{Rb}$ regulation in glioma cell lines that overexpress wild-type p53. Int J Oncol 13: 213-216, 1998.

34. Shu HK, Kim MM, Chen P, Furman F, Julin CM and Israel MA The intrinsic radioresistance of glioblastoma-derived cell lines is associated with a failure of p53 to induce p21(BAX) expression. Proc Natl Acad Sci USA 95: 14453-14458, 1998.

35. Wouters BG, Denko NC, Giaccia AJ and Brown JM: A p53 and apoptotic independent role for p21waf1 in tumour response to radiation therapy. Oncogene 18: 6540-6545, 1999.

36. Eichten A, Westfall M, Pietenpol JA and Munger K: Stabilization and functional impairment of the tumor suppressor $\mathrm{p} 53$ by the human papillomavirus type 16 E7 oncoprotein. Virology 295: 74-85, 2002

37. Song S, Gulliver GA and Lambert PF: Human papillomavirus type 16 E6 and E7 oncogenes abrogate radiation-induced DNA damage responses in vivo through p53-dependent and p53-independent pathways. Proc Natl Acad Sci USA 95: 2290-2295, 1998.

38. Katich SC, Zerfass-Thome $\mathrm{K}$ and Hoffmann I: Regulation of the Cdc25A gene by the human papillomavirus Type 16 E7 oncogene. Oncogene 20: 543-550, 2001.

39. Amellem O, Sandvik JA, Stokke T and Pettersen EO: The retinoblastoma protein-associated cell cycle arrest in S-phase under moderate hypoxia is disrupted in cells expressing HPV18 E7 oncoprotein. Br J Cancer 77: 862-872, 1998.
40. Halbert CL, Demers GW and Galloway DA: The E7 gene of human papillomavirus type 16 is sufficient for immortalization of human epithelial cells. J Virol 65: 473-478, 1991.

41. Lee WT, Hong S, Yoon SH, et al: Neuroprotective effects of agmatine on oxygen-glucose deprived primary-cultured astrocytes and nuclear translocation of nuclear factor-kappa B. Brain Res 1281: 64-70, 2009.

42. Yoshimura S, Banno Y, Nakashima S, et al: Ceramide formation leads to caspase-3 activation during hypoxic PC12 cell death. Inhibitory effects of $\mathrm{Bcl}-2$ on ceramide formation and caspase- 3 activation. J Biol Chem 273: 6921-6927, 1998.

43. Biernat W, Debiec-Rychter M and Liberski PP: Mutations of TP53, amplification of EGFR, MDM2 and CDK4, and deletions of CDKN2A in malignant astrocytomas. Pol J Pathol 49: 267-271, 1998 .

44. Ichimura K, Bolin MB, Goike HM, Schmidt EE, Moshref A and Collins VP: Deregulation of the p14ARF/MDM2/p53 pathway is a prerequisite for human astrocytic gliomas with G1-S transition control gene abnormalities. Cancer Res 60: 417-424, 2000.

45. Gomez-Manzano C, Fueyo J, Kyritsis AP, et al: Adenovirusmediated transfer of the p53 gene produces rapid and generalized death of human glioma cells via apoptosis. Cancer Res 56: 694-699, 1996.

46. Lang FF, Yung WK, Raju U, Libunao F, Terry NH and Tofilon PJ: Enhancement of radiosensitivity of wild-type p53 human glioma cells by adenovirus-mediated delivery of the p53 gene. J Neurosurg 89: 125-132, 1998.

47. Shu HK, Julin CM, Furman F, Yount GL, Haas-Kogan D and Israel MA: Overexpression of E2F1 in glioma-derived cell lines induces a p53-independent apoptosis that is further enhanced by ionizing radiation. Neuro Oncol 2: 16-21, 2000.

48. O'Connor DJ and Lu X: Stress signals induce transcriptionally inactive E2F-1 independently of p53 and Rb. Oncogene 19: 2369-2376, 2000

49. Kenzelmann Broz D and Attardi LD: In vivo analysis of p53 tumor suppressor function using genetically engineered mouse models. Carcinogenesis 31: 1311-1318, 2010. 